\title{
A Brief Analysis on Building and Enhancing the Property Management Enterprises’ Core Competitive Power
}

\author{
Liu Yang \\ School of Management, Xi'an University of Architecture and Technology, Xi'an, P.R.China \\ Ruby19299@163.com
}

\begin{abstract}
Building and enhancing core competitive power is the necessary way for property management enterprise to achieve sustainable development. In this paper, author understand and grasp deeply about the concepts and features of property management enterprise's core competitiveness, think that the way building and enhancing the enterprise's core competitiveness is to adhere to the "customer value-oriented" business philosophy, to establish a "people-oriented" corporate culture, to establish a scientific and rational performance goals and processes, to enhance the level of property management information.
\end{abstract}

Keywords-Estate management enterprise, Core competitive power, Customer value-oriented

\section{Introduction}

With the gradual standardization and increasing competition of the property management market, the owners continue to strengthen self-government and the impact of foreign property management companies, property management companies will face increasingly fierce market competition. Consequently, under the new situation in China, the only way for property management companies' subsistence and development is to understand deeply of the meaning of the concept of property management, to grasp the characteristics of core competencies, acknowledge the way to build the core competitiveness of property management, improving persistently property management companies' core competitiveness.

\section{The Concept and of Property Management Enterprise's} Core Competitiveness

\section{A The Concept of Property Management Enterprise's Core Competitiveness}

Property management is a business management practices that property management company commissioned by the owners, and thereby the client creates a comfortable "live" environment, sets a goal to protect property owners' legitimate rights and interests. Through careful planning for the owners to provide good service quality, improve the properties of internal and external environment and enhance property value and economic value, so that property can not only preserve, but also value.

Combined with the characteristics of the property management business, the core competitiveness of property management enterprises is defined that property management companies enable to form sustainable competitive advantage of high-quality, low-cost unique service capabilities in the process of market competition, through continuous learning, innovating and integrating the effective integration of skills, technology and resources.

\section{B The Characteristics of Property Management} Enterprise's Core Competitiveness

- Value. Property management enterprise's core competitiveness is not just day-to-day housing repairs, cleaning, greening and other conventional rental service capabilities and personalized services such as targeted capacity, it can bring a higher value for the owners and users by lower costs and higher quality. Furthermore, it creates long-term competitiveness and sovereignty over the industry average profit level of excess profits for property management companies.

- Peculiarity. Property management enterprise's core competitiveness forms by the unique way, along the gradual accumulation of a particular track in the long-term practice. It's a product that the property management business personalized development process, not easily imitated by competitors or beyond. Therefore, the property management companies to establish their own core competitiveness can only rely on continuous learning, and gradually hone market practice.

- Systematicness. From the system point of view, property management enterprise's core competitiveness is part of the enterprise competitiveness system, it can't be divorced from the larger system and independent existence. If only emphasizes core competitiveness of the property management and ignores synthesized competitiveness of the business competitiveness, it will affect the core competitiveness of the scarcity of these unique strategic resources into full play. Therefore, the property management companies to build and enhance core competitiveness must also pay attention to its development as overall competitiveness.

- Ductility. Has a strong core competitiveness of the "spillover effect", once the property management companies set up their own core competencies, in the relevant areas will be able to create greater interest. Therefore, the core competitiveness of enterprises can be grouped into different innovation, the creation and development of building a new foundation in a particular area and then set up their 
own competitive advantages, continue to introduce innovations.

- Dynamic. Core competencies also have their own life cycle from the produce, grow, grow until the decline. Over time, the property management enterprise's core competitiveness become a basic, general ability as the market competition, the development of science and technology, or even total loss of competitiveness. Therefore, enterprises must not stop to industrial development according to the direction of management trends, and storage conditions on their own resources, timely and enhance core competitiveness.

\section{The importance of building enhancing the core competitiveness}

\section{A Characteristics of the Property Management Industry}

Property management industry is a service industry, whose purpose is to "blending management within services." However, the service is an intangible product, measured in terms of customers' satisfaction and loyalty. To improve customers' satisfaction and loyalty, property management companies must continue to build and enhance the core competitiveness other companies difficult to follow. In addition, property management set prices or government-guiding prices at this stage, the government develop the property management industry as a low-profit nature, so the scale of property management is very important, not necessarily the size of the property management company managing a very difficult to survive and develop. The size of the business of property management must be built on its core business competitive "platform".

\section{B Intense Competition in the Market}

Property management is the little risk, low-margin industry. Many property management companies think that the benefits of property management is extensive cultivation, so that these property management companies strive for more real estate, continued foreign expansion, exacerbated by competition in the market.

In face of fierce market competition, property management companies not only provide high quality services to make competitive advantage, more importantly, must have predictive power on the market changing and grasp changing needs of the owners, so that "No I have, I have excellent." This requires a range of property management companies through the integration of form their own unique, not easily imitated by others, place and possession of a unique service capabilities and service concept - core competencies, and only rely on strength in order to obtain and maintain competitive advantage.

\section{The New Environment after WTO Accession}

Property management is the most accessible foreign areas. Western Property Management has been developed over a hundred years of history, has accumulated a wealth of management experience, forming a complete property management service system. Property management in China is only 20 years of history, its management experience, service levels and lags far behind foreign companies. After joining in the WTO, many foreign-funded enterprises set their sights on China property management market, their entrance make the market more competitive. Therefore, only local companies to speed up the construction of core competencies to the new competitive environment in an invincible position, to achieve sustainable development of enterprises.

\section{The way of building and enhancing property management companies' core competitiveness}

\section{A Adhere to the "Customer Value Orientation" Business} Philosophy, to Establish Ongoing Business Advantage

The "Customer Value Orientation( referred to as CV)" is a business philosophy that the firm's strategic decision-making, day-to-day operational management and business performance evaluation all depend on acknowledging, creating and delivering customer value ,make these as a starting point, in order to achieve the strategic objectives of maximizing customer value. Through the dynamic equilibrium considerations for customer value and enterprise value, companies continue to reduce business costs while improving customer value to establish ongoing business advantages, ensure corporate stability, healthy and rapid development.

The majority of customers of property management companies are property owners and users, for property management companies to adhere to the " Customer Value Orientation " business philosophy, they must provide the best service value for owners and users. On the one hand, for owners and users, it's service can bring greater benefits and satisfaction, the other hand, the property can be better to use functions and the "long-Kin grows new", increasing the value. Therefore property management companies not only improve the quality of service, bus also need to understand the customers' motivation to accept service. Including values, habits, identity and emotion, and on this basis, the concentration of superior resources to its research, development, renovation, upgrade, making it able to bring the object of property management services to the unique value of the core competencies.

\section{B Establish a "People-Oriented" Corporate Culture, Employees and the Companies Jointly Develop}

Corporate culture is a unique business personality, management style, corporate philosophy and comprehensive reflection of the quality of personnel. Excellent corporate culture plays an important role in the development of enterprises. First, it can motivate the entire staff internally motivated, enhance cohesion and solidarity; secondly, it will improve the business of foreign credit, expand their visibility, bring to the enterprise the social benefits difficult to estimate; third, it is also the ideological basis that enterprises reform, innovation and development strategies, and the ability of pillar enterprises to adapt to the environment.

If property management company want to achieve a lasting competitive advantage, it must foster "people-oriented" corporate culture, attention to the needs of staff, provide the ideal life-long career for them, and make efforts to create a fair competitive environment for the staff, provide more development, so that the interests of individual employees and business interests, personal development and business development combine in order to stimulate enthusiasm and creativity of employees, improve employee productivity, ensure the quality of property management services to enable enterprises to embark on a virtuous the 
development of track cycling, in order to achieve the common development of employees and enterprises.

\section{Establish Scientific and Reasonable Performance Goals, Strengthen Enterprise Management Mechanism}

Establishing and improving the modern enterprise management system is a necessary requirement to adapt the new environment WTO, is an objective requirement to achieve "enterprises according to law," is a main tool to achieve scientific and standardized management. But it can't enhance their core competitiveness only perfect enterprise management system. If the business is running in the poor implementation, the direct impact and constraints of the enterprises' core competitiveness enhancement. Therefore, strengthening the executive function is a property management company to cultivate and enhance the core competitiveness of an important safeguard.

Establishing scientific and reasonable performance goals, it is an important foundation to cultivate the property management company property management execution and build the core competitiveness of enterprises. Establishing the business goals should be objective, should always pay attention to developments in the property management market. The CEO should grasp the specific situation within the enterprise, in order to determine the implementation of corporate goals. At the same time, they also strive to make this goal a certain pressure, no pressure help to enhance the core competitiveness of enterprises; the contrary, if the pressure is too large, lacking the necessary flexibility to adjust, it may be sudden changes in external factors, manipulation business setbacks, and dampen the enthusiasm of the staff. Therefore, we must first establish the overall corporate goals, and continue to establish the specific objectives of each department, finally to establish the specific objectives of each job. Only the three goals established by the scientific and rational, it can form a system of corporate performance goals.

Establishing scientific and rational execution processes, it can improve operational efficiency. After making the performance goals, in accordance with the requirements of the tasks, property management business establish the appropriate implementation of the system processes. Include: (1) clear objectives in the implementation process of the main responsibilities and elements, broken down by responsibility and establish appropriate links; (2) set up appropriate jobs in accordance with function of the system, clear job responsibilities and job specification personnel; (3) check up on the corresponding positions of each staff appraisal by executing the results as a benchmark; (4) in accordance with the requirements of performance goals and implementation processes, appoint some appropriate staff who works not only more familiar with the goals and implementation processes, and implementation process must be to have the knowledge, skills, experience and other qualities of society, but also a sense of community and dedication to endure hardship; (5) make the final outcome of the implementation process as the target, combined with the specific requirements of the work organization, to establish a sound corresponding rules and regulations, in order to ensure the implementation of the organization goals.

\section{Improve the Level of Property Management Information}

Enterprise information management refers to collecting and transmitting and processing and managing the data from all aspects of the business links which including production, sales, human resources, research and development and financial management in corporate management effectively and systematically to implement the internal flow of information in real time and high efficiency.With the help of the Internet or local area network, enterprises can also be timely transmitting internal and external data to other departments or employees to make information sharing come true and help companies to acquire and process information quickly and accurately.

Information technology can provide the appropriate management model for the property management business, and strengthen the company and staff's awareness and practices with the objective means, thereby enhancing the staff's team spirit, in accordance with the established management. At the same time, information management systems help companies to establish business owners and user-centered, to shorten the distance between businesses and consumers, to accurately grasp the market for the property management business, improve the timeliness and quality of service. In addition information will also help enterprises to establish a performance appraisal approach, to enhance the staff's initiative and dynamism. With rational decision-making and appropriate management, property management companies can achieve coordination between departments and employees and integration, enhance the resilience, also enhance the core competitiveness of enterprises.

\section{Conclusions}

The characteristics of the property management industry and competitive market environment, companies must build and decided to enhance their core competitiveness. But this is a long process to build the core competitiveness of enterprise property management. Property management companies have to build and strengthen the core competitiveness of its own, and use the competitive strategy rational, in order to stand out in the current fierce competition in the property management market, in order to meet the needs of the development of property management under the new circumstances, to achieve survival and sustainable development.

\section{References}

[1] Collis,D.J \& Montgomery.C.A.Creating Corporate Advantage,Harvard Business Review,1998,May June.

[2] Enhua Hu,Cuiyun Mao,Yulian Ge, Based on customer value the enterprise's core competitiveness[J], Scientific Management 2002(2).

[3] Jianxin Ning, Build and enhance the core capabilities [M],BeiJing, China Logistics Publishing House, 2002. 